\title{
Optimisation of Osmotic Dehydration of Cashew Apple (Anacardium occidentale L.) in Sugar Solutions
}

\author{
P.M. Azoubel ${ }^{1, *}$ and F.E.X. Murr ${ }^{2}$ \\ ${ }^{1}$ Embrapa Semi-Arid-BR 428, km 152-Caixa Postal 23-Zona Rural-CEP 56300-970 Petrolina, PE Brazil \\ ${ }^{2}$ Department of Food Engineering-FEA-UNICAMP-Caixa Postal 6121CEP 13083-970-Campinas, SP Brazil
}

\begin{abstract}
Osmotic dehydration of cashew apple in sucrose and corn syrup solids solutions as influenced by temperature $\left(30-50{ }^{\circ} \mathrm{C}\right)$, sugar syrup concentration $(40-60 \% \mathrm{w} / \mathrm{w})$ and immersion time $(90-240 \mathrm{~min})$ was studied through response surface methodology. Responses of water loss (\%) and solid gain (\%) were fitted to polynomials, with multiple correlation coefficients ranging from 0.92 to 0.99 . The fitted functions were optimised for maximum water loss and minimised incorporation of solids in order to obtain a product resembling non-processed fruit. Three optimum sets were selected for each solute and the ascorbic acid content was determined. The ascorbic acid losses were similar to those reported for osmotic dehydration processes.
\end{abstract}

Key Words: ascorbic acid, cashew apple, osmotic dehydration, optimisation

\section{INTRODUCTION}

Cashew (Anacardium occidentale L.) is primarily cultivated for its nut from which the cashew nut kernels and the cashew nut shell liquid are derived. The cashew apple or false fruit produced is very perishable and generates a high amount of waste residues (Ortiz et al., 1982). In Brazil, the wastage rate exceeds $90 \%$ of its production (Carraro and Cunha, 1994). Economic methods for handling and processing could help facing this problem through preservation and transformation into good quality and attractive products.

Osmotic dehydration is considered a preservation method that provides high quality products by means of water removal without phase change (Lenart, 1996). During the process there is a direct contact of fruits or vegetables with a hypertonic solution, thus a driving force for water removal arises between solution and food, while the natural cell act as semipermeable membrane (Lerici et al., 1985). This process has been proposed for the production of intermediate moisture foods as a preliminary stage to air drying, pasteurisation and freezing (Silveira et al., 1996). The quantity and the rate of water removed from the materials depend on some variables and process parameters such as concentration and composition of

*To whom correspondence should be sent

(e-mail:pazoubel@cpatsa.embrapa.br).

Received 12 June 2001; revised 28 August 2003.

Food Sci Tech Int 2003;9(6):0427-7

(C) 2003 Sage Publications

ISSN: $1082-0132$

DOI: $10.1177 / 1082013203040908$ the osmotic solution, temperature, immersion time, solution/food ratio, specific surface area and agitation (Lerici et al., 1985).

Sugar uptake during the osmotic process modifies the composition and the taste of the final product (Ponting, 1973) and it can block the surface layers of the fruit, posing an additional resistance to mass exchange and lowering the rates of complementary (vacuum, convection and freeze) dehydration (Lenart and Grodecka, 1989). The water diffusion coefficients are extremely sensitive to dissolved solids content, more specifically the diffusion coefficients decrease as solids content increases (Menting et al., 1970).

As described by Lazarides et al. (1995), higher process temperatures seem to promote faster water loss through swelling and plasticising of cell membranes, faster water diffusion within the product and better mass (water) transfer characteristics on the surface due to lower viscosity of the osmotic medium.

The objective of this work was to study the osmotic dehydration of cashew apple as a function of sugar concentration, temperature and immersion time through response surface methodology (RSM) in order to identify process conditions for a high water loss at minimal solid uptakes (as an extensive sugar uptake is undesirable and the product can no longer be marketed as 'natural') and to optimise the osmotic dehydration as a pre-treatment to further processing. RSM has been used by several investigators for optimising food process operations (Mudahar et al., 1990; Vijayanand et al., 1995; Ravindra and Chattopadhyay, 2000).

As cashew apple is an excellent source of vitamin C, the ascorbic acid content was determined as a quality parameter to evaluate the final product. 


\section{MATERIAL AND METHODS}

\section{Samples}

Fresh cashew apples were obtained from a local market. The fruits were sorted visually for size, maturity level (soluble solids content from 10 to $12^{\circ}$ Brix) and physical damage. The average initial moisture content was $85.7 \% \mathrm{w} / \mathrm{w}$. Sound cashew apples were selected for osmotic dehydration. The nuts were separated manually and the apple was cut into $0.5-\mathrm{cm}$ thick slices. The average slice diameter was $5 \mathrm{~cm}$.

\section{Methods}

\section{Osmotic Dehydration Treatment}

Sucrose and corn syrup solids were used as osmotic agents (MOR-REX ${ }^{\circledR}$ 1940, Corn Products Brazil). Chemical and physical properties of corn syrup solids were as follows. Moisture content max. 5.0\%; dextrose equivalent $38-40 ; \mathrm{pH} \quad 4.5-5.5 ;$ carbohydrates $(\%$ dry basis): dextrose 15, maltose 12; other sugars 73 . The osmotic solution was prepared by dissolving the required quantity of sugar in distilled water, under the conditions given by the central composite experimental design (Table 1).

Slices of cashew apple were submerged in the osmotic solution in $600 \mathrm{~mL}$ beakers and placed inside a temperature-agitation controlled shaker (Tecnal, TE421). Gentle agitation of $80 \mathrm{rpm}$ was necessary for a good mixing of the osmotic medium. The weight ratio of osmotic medium to fruit samples was 10:1 to avoid significant dilution of the medium and subsequent decrease of the driving force during the process. After being removed from the sugar syrup, samples were drained and the excess of solution at the surface was removed with absorbent paper for posterior weight.

\section{Experimental Design}

The optimum processing conditions were considered and maximised water loss and minimised solids gain were determined by using response surface methodology (RSM). A central composite rotatable design (Khuri and Cornell, 1996) was used for designing the experiments for osmotic dehydration of cashew apple using three factors (variables range based on values commonly used for fruit osmotic processes): temperature $\left(30-50{ }^{\circ} \mathrm{C}\right)$, concentration $(40-60 \% \mathrm{w} / \mathrm{w})$ and time (90-240 min). Five levels of each variable were chosen for study, including the centre point and two axial points (Khuri and Cornell, 1996), and 17 combinations were performed, including three replications of the centre point (Table 1). The experimental design was repeated for each solute.

It was assumed that a mathematical function, $\varphi$, exists for the response variable $Y$ (water loss and solids gain), in terms of three independent process variables (Khuri and Cornell, 1996), temperature, concentration and time:

$$
\begin{aligned}
Y=\varphi & =(T, C, t)=\beta_{0}+\beta_{1} t+\beta_{2} C+\beta_{3} t+\beta_{11} T^{2} \\
& +\beta_{22} C^{2}+\beta_{33} t^{2}+\beta_{12} T \cdot C+\beta_{13} T \cdot t+\beta_{23} C \cdot t
\end{aligned}
$$

Table 1. Experimental data for water loss (WL) and solids gain (SG) under different treatment conditions of

\begin{tabular}{|c|c|c|c|c|c|c|c|}
\hline \multirow[b]{2}{*}{ Treatment } & \multirow[b]{2}{*}{$T\left({ }^{\circ} \mathrm{C}\right)$} & \multirow[b]{2}{*}{$C^{\mathrm{a}}(\%, \mathrm{w} / \mathrm{w})$} & \multirow[b]{2}{*}{$t(\min )$} & \multicolumn{2}{|c|}{ Sucrose } & \multicolumn{2}{|c|}{ Corn Syrup } \\
\hline & & & & WL (\%) & SG (\%) & WL (\%) & SG (\%) \\
\hline 1 & 34 & 44 & 120 & 28.01 & 4.20 & 24.20 & 1.00 \\
\hline 2 & 46 & 44 & 120 & 51.07 & 2.67 & 35.72 & 1.65 \\
\hline 3 & 34 & 56 & 120 & 32.67 & 2.83 & 26.97 & 1.34 \\
\hline 4 & 46 & 56 & 120 & 53.94 & 5.03 & 42.39 & 2.26 \\
\hline 5 & 34 & 44 & 210 & 39.55 & 4.67 & 32.06 & 1.61 \\
\hline 6 & 46 & 44 & 210 & 53.90 & 5.82 & 50.71 & 1.98 \\
\hline 7 & 34 & 56 & 210 & 43.64 & 3.72 & 38.03 & 2.02 \\
\hline 8 & 46 & 56 & 210 & 64.14 & 6.76 & 56.55 & 2.65 \\
\hline 9 & 40 & 50 & 165 & 41.11 & 3.51 & 36.12 & 1.14 \\
\hline 10 & 40 & 50 & 165 & 41.33 & 3.56 & 38.59 & 1.18 \\
\hline 11 & 40 & 50 & 165 & 42.65 & 3.34 & 37.80 & 1.15 \\
\hline 12 & 30 & 50 & 165 & 32.99 & 2.10 & 26.74 & 0.45 \\
\hline 13 & 50 & 50 & 165 & 61.54 & 4.29 & 49.51 & 1.81 \\
\hline 14 & 40 & 40 & 165 & 35.72 & 3.52 & 26.91 & 1.38 \\
\hline 15 & 40 & 60 & 165 & 45.96 & 4.17 & 36.02 & 2.01 \\
\hline 16 & 40 & 50 & 90 & 31.74 & 3.47 & 29.39 & 1.93 \\
\hline 17 & 40 & 50 & 240 & 55.32 & 6.18 & 45.95 & 2.99 \\
\hline
\end{tabular}
temperature, sugar concentration $(C)$ and time.

${ }^{a}$ Water activity of sucrose solutions: $0.962(40 \%) ; 0.954(44 \%) ; 0.939(50 \%) ; 0.920(56 \%) ; 0.899(60 \%)$. Water activity of corn syrup solutions: 0.975 (40\%); 0.966 (44\%); 0.959 (50\%); 0.940 (56\%); 0.927 (60\%). 
Regression coefficients, analysis of variance, test of lack of fit and the generation of three-dimensional graphs were calculated using the Statistica 5.0 package (Statsoft, 1997).

The average relative deviation $(P)$ was used to evaluate if the proposed models for water loss and solids gain were predictable, according to Equation (2):

$$
P=\frac{100}{N} \sum_{i=1}^{N} \frac{\left|V_{P}-V_{o}\right|}{V_{o}}
$$

where $P$ is the average relative deviation $(\%), V_{P}$ the calculated values from the model (Equation (1)), $V_{o}$ the experimental values and $N$ the number of experimental points. Values of $P$ less than or equal to $10 \%$ are considered to fit the experimental data satisfactorily (Lomauro et al., 1985).

\section{Solid Gain and Water Loss}

Water loss and the solids uptake were determined by gravimetric measurement, by assuming that, under the conditions used, the solutes initially present in the fruit slices do not diffuse against the total solids concentration gradient into the concentrated osmotic solution (Hawkes and Flink, 1978). The total wet weight (tw) is the weight of the cashew slice at the time of sampling, determined upon removal from the solution, and the total solids weight (ws) determined in a vacuum oven at $70{ }^{\circ} \mathrm{C}$ for $24 \mathrm{~h}$. The solids gain (g solids/ $100 \mathrm{~g}$ initial wet cashew apple) can be defined as:

$$
\mathrm{SG}=\frac{w s-w s_{o}}{w_{o}} \times 100
$$

and the water loss ( $\mathrm{g}$ water $/ 100 \mathrm{~g}$ initial wet cashew apple) as:

$$
\mathrm{WL}=\frac{w w_{o}-(t w-w s)}{w_{o}} \times 100
$$

where $w s_{o}$ is the initial weight of solids, $w w_{o}$ the initial weight of water and $w_{o}$ the initial wet weight of the sample.

Each experimental run was performed in triplicate and the reported values are based on average values, the error being less than $0.5 \%$.

\section{Ascorbic Acid Determination}

Ascorbic acid content was determined based on the 2,6-dichlorophenol indophenol titration method. The dye, which is blue in alkaline solution and red in acid solution, is reduced by ascorbic acid to a colourless form. The method is quantitative and practically specific for ascorbic acid in solutions in the $\mathrm{pH}$ range 1-3.5 (Ranganna, 1977). Determinations were made on triplicate and the results were reported as an average (error less than $2 \%$ ).

\section{RESULTS AND DISCUSSION}

The experimental values for water loss and solids gain under different treatment conditions (Table 1) showed that the water removal was always higher than the osmotic agent uptake, in agreement with the results of other workers (Lazarides et al., 1995; Lenart, 1996). Water loss and solids gain were higher when sucrose was used as osmotic agent. The driving force for the mass transfer is provided by the higher osmotic pressure of the sucrose solutions. In addition, the corn syrup solids solutions had a higher viscosity and polysaccharides content. The larger the solute size, the lower the sugar uptake under fixed process conditions (Contreras and Smyrl, 1981; Lerici et al., 1985).

\section{Response Surface Analysis}

Regression coefficients for the second-order polynomial equations are displayed in Table 2 . The resulting equations were tested for adequacy and fitness by analysis of variance (ANOVA). Table 3 summarises the results for linear, quadratic and cross-product terms for water loss and solid gain for each solute; some nonsignificant terms $(p>0.05)$ were eliminated. For water loss, the temperature $(T)$ was the most important factor. There was no interaction among factors, meaning that water loss was a simple function of temperature, sugar concentration and immersion time.

Immersion time and temperature were the most significant factors for solid gain. The temperature also interacted with sugar concentration and time in determining the uptake of solids.

Table 2. Values of the second-order polynomial regression coefficients.

\begin{tabular}{lccccc}
\hline & \multicolumn{2}{c}{ Sucrose } & & \multicolumn{2}{c}{ Corn Syrup } \\
\cline { 2 - 3 } \cline { 5 - 6 } Coefficients & WL & SG & & WL & SG \\
\hline$\beta_{\circ}$ & 32.102 & 69.674 & & -55.790 & 17.756 \\
$\beta_{1}$ & -3.237 & -1.142 & & 1.255 & 0.013 \\
$\beta_{2}$ & 0.479 & -1.428 & & 0.448 & -0.581 \\
$\beta_{3}$ & 0.123 & -0.144 & & 0.124 & -0.060 \\
$\beta_{11}$ & 0.060 & NS & & NS & NS \\
$\beta_{22}$ & NS & 0.007 & & NS & 0.005 \\
$\beta_{33}$ & NS & 0.0003 & & NS & 0.0002 \\
$\beta_{12}$ & NS & 0.020 & & NS & 0.002 \\
$\beta_{13}$ & NS & 0.002 & & NS & 0.0003 \\
$\beta_{23}$ & NS & NS & NS & NS \\
\hline
\end{tabular}

NS: non-significant $(p>0.05)$. 
Table 3. Analysis of variance for water loss (WL) and solids gain (SG) in the osmotic dehydration of cashew apple in sucrose and corn syrup solids solutions.

\begin{tabular}{|c|c|c|c|c|c|c|}
\hline \multirow[b]{2}{*}{ Osmotic Solution } & \multicolumn{3}{|c|}{ WL } & \multicolumn{3}{|c|}{ SG } \\
\hline & $d f$ & (Mean square) & $F$ & $d f$ & Mean square & $F$ \\
\hline \multicolumn{7}{|l|}{ Sucrose } \\
\hline Model & 4 & 442.337 & $65.56^{*}$ & 7 & 3.432 & $23.87^{*}$ \\
\hline \multicolumn{7}{|l|}{ Linear } \\
\hline$T$ & 1 & 1185.446 & $175.70^{*}$ & 1 & 5.328 & $36.74 *$ \\
\hline$c$ & 1 & 111.737 & $16.56^{*}$ & 1 & 0.314 & $2.17^{*}$ \\
\hline$T$ & 1 & 413.381 & $61.27^{*}$ & 1 & 8.507 & $58.67^{*}$ \\
\hline \multicolumn{7}{|l|}{ Quadratic } \\
\hline$T$ & 1 & 58.785 & $8.71^{*}$ & NS & - & - \\
\hline C & NS & - & - & 1 & 0.699 & $4.82 *$ \\
\hline$t$ & NS & - & - & 1 & 4.217 & $29.08^{*}$ \\
\hline \multicolumn{7}{|l|}{ Cross-prod. } \\
\hline TC & NS & - & - & 1 & 3.968 & $27.37^{*}$ \\
\hline$T t$ & NS & - & - & 1 & 1.540 & $10.62 *$ \\
\hline$C t$ & NS & - & - & NS & - & - \\
\hline Residual & 12 & 6.747 & & 9 & 0.145 & \\
\hline Lack of fit & 10 & 7.957 & 11.45 (NS) & 7 & 0.181 & 13.92 (NS) \\
\hline Pure error & 2 & 0.695 & & 2 & 0.013 & \\
\hline TOTAL & 16 & & & 16 & & \\
\hline$R^{2}$ & 0.956 & & & 0.945 & & \\
\hline \multicolumn{7}{|l|}{ Corn syrup } \\
\hline \multicolumn{7}{|l|}{ Linear } \\
\hline$T$ & 1 & 768.460 & $93.08^{*}$ & 1 & 1.716 & $286.00 *$ \\
\hline$c$ & 1 & 97.946 & $11.86^{*}$ & 1 & 0.700 & $116.67^{*}$ \\
\hline \multirow[t]{2}{*}{$t$} & 1 & 422.441 & $51.17^{*}$ & 1 & 1.054 & $175.67^{*}$ \\
\hline & NS & - & & & & \\
\hline Quadratic & & - & & & & \\
\hline$T$ & NS & - & - & NS & - & - \\
\hline$c$ & NS & & - & 1 & 0.466 & $77.67^{*}$ \\
\hline$t$ & NS & - & - & 1 & 2.679 & $446.50 *$ \\
\hline Cross-prod. & & - & & & & \\
\hline$T C$ & NS & - & - & 1 & 0.033 & $5.50 *$ \\
\hline$T t$ & NS & & - & 1 & 0.040 & $6.67^{*}$ \\
\hline$C t$ & NS & & - & NS & - & - \\
\hline Residual & 13 & 8.256 & & 9 & 0.006 & \\
\hline Lack of fit & 11 & 9.467 & 5.924 (NS) & 7 & 0.008 & 16.00 (NS) \\
\hline Pure error & 2 & 1.598 & & 2 & 0.001 & \\
\hline Total & 16 & & & 16 & & \\
\hline$R^{2}$ & 0.923 & & & & & \\
\hline
\end{tabular}

NS: non-significant. *Significant at $5 \%$ level.

The statistical analysis indicated that the proposed models for water loss and solid gain were adequate, having no lack of fit and very satisfactory values of $R^{2}$ (correlation coefficients).

\section{Optimisation}

The highest values of solid uptake were observed at treatment temperatures above $45^{\circ} \mathrm{C}$, which were probably due to the membrane swelling and plasticising effect, which improves the cell membrane permeability to sugar molecules. However, at this temperature the cashew apple slices changed colour and texture.

Since the optimum response of each variable did not fall exactly in the same region (Figures 1 and 2) the solid gain/water loss ratio (SG/WL) was a good indicator of the extent to which the process succeeds the maximisation of water loss and the minimisation of solid gain, as used by Ravindra and Chattopadhyay (2000) in the osmotic dehydration of potato cubes in a binary solution of salt and sugar. Lazarides et al. (1995) also suggested the WL/SG ratio in the dehydration of apple as an indicative of process efficiency.

Variation of SG/WL ratio as a function of sucrose concentration and temperature followed a quadratic pattern (Figure 1(a)). A continuous increase in the $\mathrm{SG} / \mathrm{WL}$ ratio was observed with increase in temperature when higher sucrose solution concentration was used (more than $54 \% \mathrm{w} / \mathrm{w}$ ). However at low concentration 
(a)

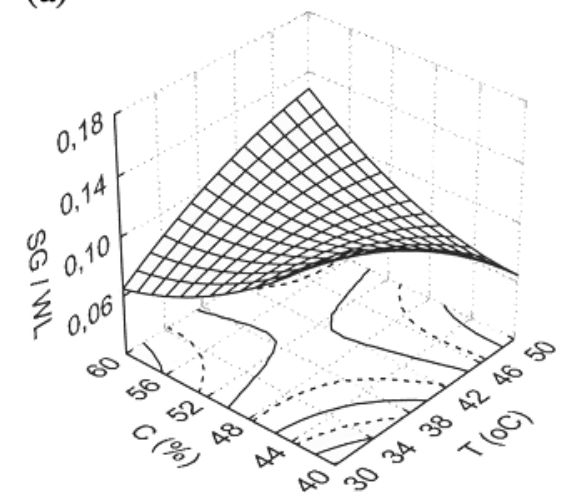

(b)

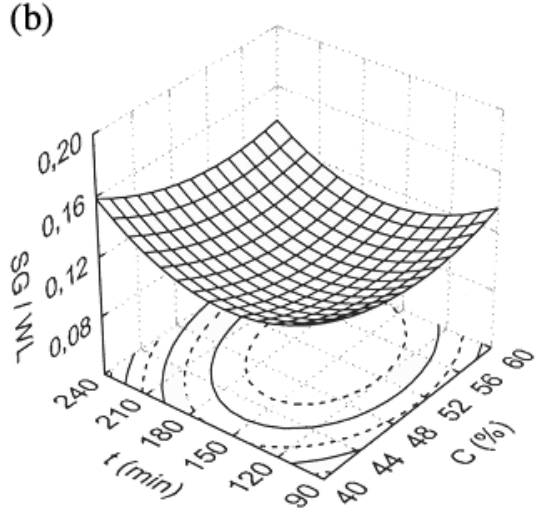

Figure 1. Response surfaces for SG/WL ratio as a function of: (a) Sucrose concentration and process temperature at $165 \mathrm{~min}$ time; (b) Immersion time and sucrose concentration at $40^{\circ} \mathrm{C}$.
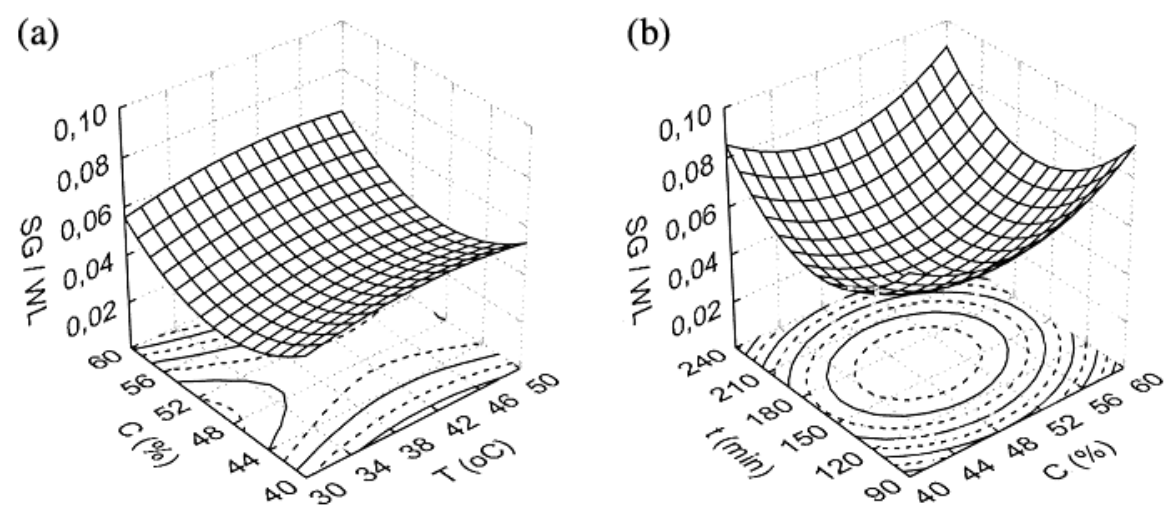

Figure 2. Response surfaces for SG/WL ratio as a function of: (a) Corn syrup solids concentration and process temperature at $165 \mathrm{~min}$ time; (b) Immersion time and corn syrup solids concentration at $40^{\circ} \mathrm{C}$.

values (less than $50 \% \mathrm{w} / \mathrm{w}$ ) the ratio decreased sharply as temperature increased.

There was a flat region in the surface of SG/WL ratio as a function of immersion time and sucrose concentration (Figure 1(b)) where many combinations of the process parameters generate optimum response values. A similar behaviour was observed for the dehydration with corn syrup solids solution (Figure 2(b)), nevertheless SG/WL values for sucrose solution were higher. A strong curvature of the surfaces pointed out the high significance of pure quadratic terms.

The response surface of SG/WL in the osmotic process using corn syrup versus syrup concentration and temperature (Figure 2(a)) showed that solution concentration ranging from 43 to $56 \% \mathrm{w} / \mathrm{w}$, independent of the temperature used, gave lower values of SG/WL.

The same optimum conditions sets were observed for both solutes (Table 4), even at lower ratio values found for corn syrup, since its higher polisaccharides content interfere in the solids gain, as discussed before.
The optimised sets were verified and the models (Table 2) were able to predict water loss and solids gain with satisfactory average deviation values $(<10 \%)$.

\section{Ascorbic Acid Content}

Any osmotic conditions resulted in vitamin $\mathrm{C}$ loss (Table 5). Querido (2000) reported vitamin C loss of 16.97 and $25.22 \%$ in the osmotic dehydration of cashew apple slices in a $64.5^{\circ}$ Brix sucrose solution for $180 \mathrm{~min}$ $\left(35^{\circ} \mathrm{C}\right)$ and $100 \mathrm{~min}\left(40^{\circ} \mathrm{C}\right)$, respectively.

The ascorbic acid losses observed in the two solutes tested were identical for the same dehydration condition. Similar observations were made on kiwi (Vial et al., 1991).

The loss level was higher at $42^{\circ} \mathrm{C}$ (around $44 \%$ ), at low temperature, ascorbic acid losses during osmotic dehydration might be attributed to the leaching of the vitamin from the product to the osmotic solution (Islam and Flink, 1982) during the osmotic process of potato slices in a sucrose/salt solution. When temperature is high, chemical degradation as well as 
Table 4. Optimised conditions for osmotic dehydration of cashew apple slices in sucrose and corn syrup solids.

\begin{tabular}{lccc}
\hline & \multicolumn{3}{c}{ Optimum Conditions } \\
\cline { 2 - 4 } Factor & $A$ & $B$ & $C$ \\
\hline Temperature $\left({ }^{\circ} \mathrm{C}\right)$ & 30 & 34 & 42 \\
Concentration $(\% \mathrm{w} / \mathrm{w})$ & 60 & 52 & 44 \\
Time $($ min) & 160 & 165 & 120 \\
Sucrose & & & \\
Model & 37.41 & 36.61 & 37.82 \\
WL $(\%)$ & 5.17 & 6.51 & 6.51 \\
SG (\%) & & & \\
Observed & 39.94 & 38.73 & 39.39 \\
WL (\%) & 5.31 & 6.12 & 6.32 \\
SG (\%) & $5.55(\mathrm{WL})$ & $3.80(\mathrm{SG})$ & \\
P (\%) & & & \\
Corn Syrup & 28.58 & 30.64 & 31.51 \\
Model & 1.46 & 1.83 & 2.76 \\
WL (\%) & & & \\
SG (\%) & 25.72 & 28.27 & 32.50 \\
Observed & 1.45 & 1.97 & 2.43 \\
WL (\%) & $6.97(\mathrm{WL})$ & $6.68(\mathrm{SG})$ & \\
SG (\%) & & & \\
P (\%) & &
\end{tabular}

Table 5. Influence of processing conditions on vitamin C.

\begin{tabular}{|c|c|c|c|c|c|c|c|}
\hline \multirow[b]{2}{*}{ Ascorbic Acid } & \multirow[b]{2}{*}{ Fresh Fruit } & \multicolumn{3}{|c|}{ Sucrose } & \multicolumn{3}{|c|}{ Corn Syrup } \\
\hline & & $A$ & $B$ & $C$ & $A$ & $B$ & $C$ \\
\hline $\mathrm{mg} / 100 \mathrm{~g}$ treated fruit $^{\mathrm{a}}$ & & 205.77 & 196.27 & 173.49 & 178.58 & 177.00 & 162.91 \\
\hline $\mathrm{mg} / 100 \mathrm{~g}$ fresh fruit ${ }^{\mathrm{b}}$ & 204.78 & 133.36 & 130.53 & 114.58 & 134.37 & 130.3 & 116.61 \\
\hline Loss (\%) & & 34.98 & 36.26 & 44.05 & 34.38 & 36.37 & 43.06 \\
\hline Moisture (\% wb) & 85.70 & 70.03 & 69.72 & 69.22 & 79.18 & 79.67 & 78.74 \\
\hline$a_{w}$ & 0.989 & 0.968 & 0.970 & 0.975 & 0.986 & 0.983 & 0.987 \\
\hline
\end{tabular}

${ }^{\mathrm{a}}$ In terms of total solids base, including solute uptake. ${ }^{\mathrm{b}}$ In terms of initial dry matter content, calculated based on moisture content.

diffusion seemed to be the most significant phenomena (Vial et al., 1991).

\section{ACKNOWLEDGEMENTS}

The authors gratefully acknowledge the financial support of FAPESP (State of São Paulo Research Foundation). They also thank Corn Products Brasil for supplying the corn syrup solids.

\section{REFERENCES}

Carraro F. and Cunha M.M. (1994). Manual de exportação de frutas. Brasília: MAARA-SDR-FRUPEX/IICA.

Contreras J.E. and Smyrl T.G. (1981). An Evaluation of osmotic concentration of apple rings using corn syrup solids solutions. Canadian Institute of Food Science and Technology 14: 310-314.
Hawkes J. and Flink J. (1978). Osmotic concentration of papaya: influence of process variables on the quality. Journal of Food Processing and Preservation 2: 265-284.

Islam M. N. and Flink L. N. (1982). Dehydration of potato II - Osmotic concentration and its effect on air drying behavior. Journal of Food Technology 17: 387-403.

Khuri A.J. and Cornell F.A. (1996). Response Surfaces: Design and Analyses. New York: Marcel Dekker.

Lazarides H.N., Katsanidis E. and Nickolaidis A. (1995). Mass transfer during osmotic preconcentration aiming at minimal solid uptake. Journal of Food Engineering 25: $151-166$

Lenart A. (1996). Osmo-convective drying of fruits and vegetables: technology and application. Drying Technology 14: 391-413.

Lenart A. and Grodecka E. (1989). Influence of the kind of osmotic substance on the kinetics of convection drying of apples and carrots. Food Technology Nutrition 18: $27-35$.

Lerici C.R., Dalla Rosa M. and Bartolucci L. (1985). Osmotic dehydration of fruits: influence of osmotic 
agents on drying behavior and product quality. Journal of Food Science 50: 1217-1220.

Lomauro C.J., Bakshi A.S. and Labuza T.P. (1985). Evaluation of food moisture sorption isotherm equations. Part I: fruit, vegetable and meat products. Lebensmittel-Wissenschaft and Technologies 18: 112-122.

Menting L.C., Hoegstad B. and Thijssen H.A.C. (1970). Diffusion coefficients of water and organic volatiles in carbohydrates-water systems. Journal of Food Science 5: 111.

Mudahar G.S., Toledo R.T. and Jen J.J. (1990). A response surface methodology approach to optimize potato dehydration process. Journal of Food Processing and Preservation 14: 93-106.

Ortiz A.J., Cooke R.D. and Quiros M.R.A. (1982). The processing of a date-like caramel from cashew apple. Tropical Science 24: 29-38.

Ponting J.D. (1973). Osmotic dehydration of fruits - recent modifications and applications. Process Biochemistry 8: 18-20.

Querido A.F. (2000). Otimização e comparação dos processos de desidratação osmótica a vácuo e a pressão ambiente de pseudofruto de caju. Master Thesis, Universidade Estadual de Campinas, Campinas, Brasil.

Ranganna S. (1977). Manual of Analysis of Fruit and Vegetables products, p. 634, New Delhi: Mc-Graw Hill Publishing Company.

Ravindra M.R. and Chattopadhyay P.K. (2000). Optimisation of osmotic preconcentration and fluidised bed drying dehydrated quick-cooking potato cubes. Journal of Food Engineering 44: 5-11.

Silveira E.T.F., Rahman M.S. and Buckle K.A. (1996). Osmotic dehydration of pineapple: kinetics and product quality. Food Research International 29: 227-233.

Statsoft (1997). Statistica for Windows. Tulsa, USA: Statsoft.

Vijayanand P., Chand N. and Eipeson W.E. (1995). Optimization of osmotic dehydration of cauliflower. Journal of Food Processing and Preservation 19: 229-242.

Vial C., Guilbert S. and Cuq J.L. (1991). Osmotic dehydration of kiwi fruits: influence of process variables on the color and ascorbic acid content. Science des Aliments 11: 63-84. 